\title{
Identification of two key genes controlling chill haze stability of beer in barley (Hordeum vulgare $\mathrm{L}$ )
}

\author{
Lingzhen Ye ${ }^{1,2}$, Yuqing Huang ${ }^{1}$, Fei Dai ${ }^{1}$, Huajiang Ning ${ }^{1}$, Chengdao $\mathrm{Li}^{2}$, Meixue Zhou ${ }^{3}$ and Guoping Zhang ${ }^{1 *}$
}

\begin{abstract}
Background: In bright beer, haze formation is a serious quality problem, degrading beer quality and reducing its shelf life. The quality of barley (Hordeum vulgare L) malt, as the main raw material for beer brewing, largely affects the colloidal stability of beer.

Results: In this study, the genetic mechanism of the factors affecting beer haze stability in barley was studied. Quantitative trait loci (QTL) analysis of alcohol chill haze (ACH) in beer was carried out using a Franklin/Yerong double haploid (DH) population. One QTL, named as $\mathrm{QACH}$, was detected for ACH, and it was located on the position of about $108 \mathrm{cM}$ in chromosome $4 \mathrm{H}$ and can explain about $20 \%$ of the phenotypic variation. Two key haze active proteins, BATI-CMb and BATI-CMd were identified by proteomics analysis. Bioinformatics analysis showed that BATI-CMb and $B A T I-C M d$ had the same position as qACH in the chromosome. It may be deduced that BATI-CMb and BATI-CMd are candidate genes for $q A C H$, controlling colloidal stability of beer. Polymorphism comparison between Yerong and Franklin in the nucleotide and amino acid sequence of BATI-CMb and BATI-CMd detected the corresponding gene specific markers, which could be used in marker-assisted selection for malt barley breeding.
\end{abstract}

Conclusions: We identified a novel QTL, GACH controlling chill haze of beer, and two key haze active proteins, BATI-CMb and BATI-CMd. And further analysis showed that BATI-CMb and BATI-CMd might be the candidate genes associated with beer chill haze.

Keywords: Barley, Beer haze, Malt, Quantitative trait loci (QTL)

\section{Background}

Beer is one of the oldest and also most widely consumed alcoholic beverages, and it is commonly produced from malt barley as main raw material. Haze is often developed during beer storage or transportation, resulting in reduced shelf life and degraded quality of beer. Beer haze can be divided into biological and non-biological ones. The biological haze can be avoided or reduced during beer processing, as it is caused by the wild yeast or bacteria due to poor hygiene. In contrast, the non-biological haze is not easy to be dealt with, because it is derived from brewing raw materials, such as malt barley.

The most common non-biological haze is attributed to interactions between haze active proteins and certain

\footnotetext{
* Correspondence: zhanggp@zju.edu.cn

'Agronomy Department, Zhejiang University, Hangzhou 310058, People's Republic of China

Full list of author information is available at the end of the article
}

polyphenols [1-3]. Moreover, non-biological haze is commonly divided into chill haze and permanent haze. Chill haze is formed when beer is chilled to $0{ }^{\circ} \mathrm{C}$ and it may re-dissolve when the beer is warmed to $20{ }^{\circ} \mathrm{C}$ or more, while permanent haze will remain in beer even at higher temperature. In fact, chill haze is a precursor of permanent haze, so understanding of non-biological haze formation in beer should be started from chill haze.

Some technical approaches have been available for reducing haze formation in beer, such as silica $[4,5]$ and polyvinylpolypyrrolidone (PVPP) adsorbent [6] treatments, but these treatments will increase the cost of beer production and deteriorate some flavor due to reduced relevant proteins, such as foam active protein. As non-biological haze formation is closely related to malt barley, the one of most efficient ways for controlling colloidal haze formation is development of the malt barley cultivars with lower content of haze-related proteins. 
Beer contains lots of barley and yeast proteins, which affect beer haze stability. Many barley proteins, including hordeins [1], dimeric $\alpha$-amylase inhibitor (BDAI-1) [7], $\mathrm{CMb}$ component of tetrameric $\alpha$-amylase inhibitor $(\mathrm{CMb})$ [7] and trypsin inhibitor CMe precursor (BTI$\mathrm{CMe}$ ) [8-11] have been considered as the haze active proteins. However, the main factors that act as the dominant role in beer haze formation are not clearly known. Meanwhile, although a great number of researches have been done on genetics and relevant genes or molecular markers of many malt quality traits, such as diastatic power [12, 13], seed dormancy [14], and protein content $[12,13]$, very few reports could be found about genetic controlling of haze active proteins.

In this study, we identified a QTL controlling haze formation in beer through comparing the difference in haze formation among 177 lines of a double-haploid (DH) population as well as the two parents, and found two haze active proteins through proteomics analysis. In addition, the mechanism in genotypic difference of haze formation was also proposed.

\section{Methods}

\section{Plant materials and field trial}

A double haploid $(\mathrm{DH})$ population consisting of 177 lines, derived from a cross between Franklin and Yerong was used in this study. The field experiments were conducted in two growing seasons of 2009-2010 and 20102011 on the experimental farm of Zhejiang University (Huajiachi campus, Hangzhou, China). All DH lines and the two parents were sown in early November with adjacent plots in a field and each plot consisted of 10 rows with $2 \mathrm{~m}$ length and $0.25 \mathrm{~m}$ between rows [15]. In each row 50 seeds were sown. Other field managements, including fertilization, weed and disease control, were the same as applied locally. At maturity, the grains in 8 middle rows of each plot were harvested and stored in a refrigerator at $4^{\circ} \mathrm{Cfor}$ further measurements.

\section{Preparation of beer samples}

The grains of each line and parents of the DH population were micro-malted according to Cai et al. [16] and micro-brewed according to Stewart et al. [17] with some modification. The procedures were briefly as follows: $200 \mathrm{~g}$ grain sample was micro-malted by Joe White malting system; and then $50 \mathrm{~g}$ of malt grist (ground by a Buhler Miag mill) with three replications was mashed in a temperature-controlled mash bath according to a European Brewery Convention (EBC) method. Water was added to a final weight of $450 \mathrm{~g}$ (grist/water ratio $1: 8$, the wort concentration was about $8.3 \mathrm{Bx}$ ) after finishing the mash process, and then wort was filtered by a filter paper. After adjusting the $\mathrm{pH}$ of the wort to 5.4 with $1 \mathrm{~N} \mathrm{H}_{3} \mathrm{PO}_{4}$, the wort was sterilized at $105{ }^{\circ} \mathrm{C}$ for 30 min without hops; Then commercial beer dry yeast (JJB, the UK) was incubated with wort at a ratio of $0.6 \%$. The wort was fermented at a constant temperature of $8{ }^{\circ} \mathrm{C}$ for 13 days. Finally, beer was filtered by a sheet filter and bottled for further analysis.

\section{Trait assay}

The alcohol-chill test was conducted to predict the colloidal stability of beer according to Chapon [18]. The procedures were as follows: $5 \%$ pure ethanol was added into beer sample and carefully mixed, frozen at $-8{ }^{\circ} \mathrm{C}$ for $40 \mathrm{~min}$, then measured by a turbimeter (HANNA HI93124). In this study, EBC unit was used for alcoholchill haze degree (ACHD), characterizing the beer status at racking or during aging $[19,20]$.

\section{QTL analysis}

The statistical analysis of phenotypic data, including variance and correlation analysis of ACHD in two
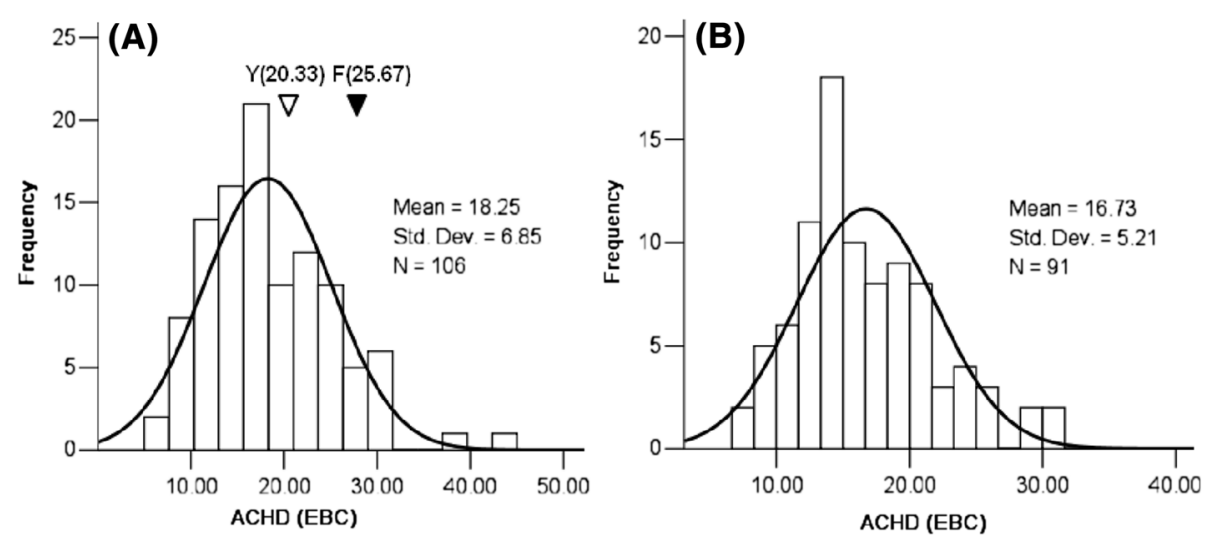

Fig. 1 Frequency distribution of alcohol chill haze degree (ACHD) in a Franklin/Yerong DH population. a,2009-2010 growing season; b, 2010-2011 growing season 
Table 1 QTLs identified for ACHD in aFranklin $\times$ Yerong DH population

\begin{tabular}{llllllllll}
\hline Year & Chr. & Closest marker & Position $(c M)$ & LOD & $R^{2}(\%)$ & Additive & $Y^{*}(E B C)$ & $F^{*}(E B C)$ & QTL \\
\hline $2009-2010$ & $4 \mathrm{H}$ & bPb-8164 & 108.093 & 3.88 & 20.3 & 2.35 & 14.31 & 18.73 & $q A C H$ \\
$2010-2011$ & $4 H$ & bPb-8164 & 108.093 & 4.85 & 19.3 & 3.05 & 14.87 & 20.94 & aACH
\end{tabular}

*: $\mathrm{Y}$ and $\mathrm{F}$ indicated that the genotypes of marker bPb-8164belong to the same groups of Yerong and Franklin, respectively. These values were the mean ACHD of each group

growing seasons were accomplished using SPSS 13.0. The genetic linkage map was constructed using 496 Diversity Array Technology (DArT) and 28 microsatellite markers by software Jionmap 4 [21]. QTLs were analyzed using software MapQTL5.0 [22]. Firstly, interval mapping (IM) was done in QTL analysis, and then the closest marker with highest logarithm of the odds (LOD) score was selected as a cofactor for testing multiple QTL model (MQM). A threshold LOD > 3 was used to prove the presence of a QTL.

\section{Preparation of protein samples}

The alcohol chill treated beers were centrifuged at $15000 \mathrm{~g}$ for $20 \mathrm{~min}$ at $0{ }^{\circ} \mathrm{C}$. Turbid sediments and clear supernatants were then collected as ACH and control, respectively.

\section{Proteomics analysis}

After mixed with protein loading buffer, the collected control and $\mathrm{ACH}$ samples were treated at $100{ }^{\circ} \mathrm{C}$ for 5 min. Then Tricine-SDS-PAGE was carried out as

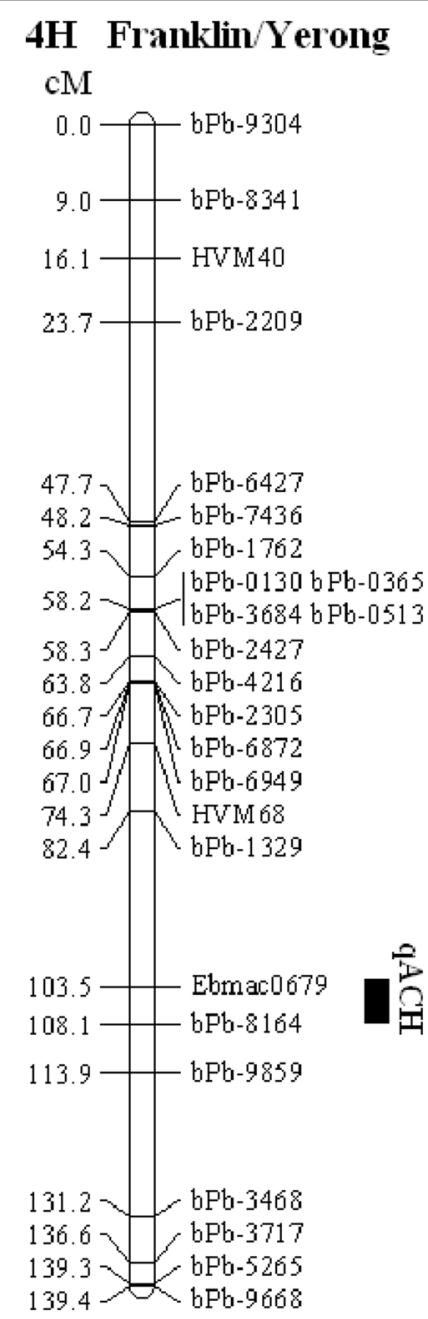

4H Barque 73/CPI 71284-48

$\mathrm{cM}$

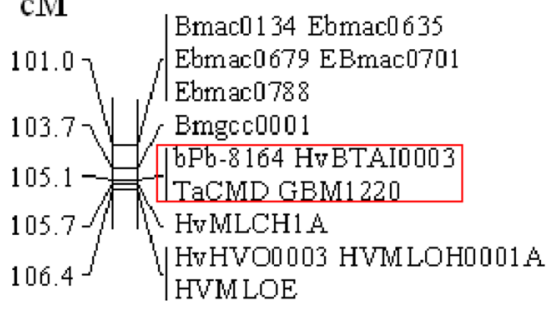

genetic map of Barque/CPI 71284-48population (Hearnden et al. 2007) was added to the right for comparison 
described by Schagger [23]. The gels were stained with Coomassie blue G250. The special protein band of about $15 \mathrm{kDa}$ was excised and digested by trypsin (Promega V5280) for High performance liquid chromatographytandem mass spectrometry (LC-MS/MS) analysis.

LC-MS/MS analysis of the digested proteins was performed using a Thermo Scientific Surveyor Plus HPLC system coupled to a Thermo Electron LTQ-Orbitrap mass spectrometer. Chromatographic separations were conducted on a reverse-phase capillary column (100 $\mu$ mi.d., $10 \mathrm{~cm}$ long, $3 \mu \mathrm{m}$ resin from Michrom Bioresources, Auburn, CA) with a mobile phase A of solution containing $0.1 \%$ formic acid, $2 \%$ acetonitrile and a mobile phase $\mathrm{B}$ of acetonitrile containing $0.1 \%$ formic acid at a flow rate of $300 \mathrm{~nL} / \mathrm{min}$. The gradient was gradually increased from $5 \%$ to $35 \%$ of solvent B $(0.1 \%$ formic acid/ACN) within $120 \mathrm{~min}$. The mass analysis was performed in a positive ionization mode. The operation conditions were as follows: ionspray voltage, $1.85 \mathrm{kV}$; source temperature, $220{ }^{\circ} \mathrm{C}$; resolution ratio, 60000; and scanning scope, $400 \sim 2000 \mathrm{Da}$. For data processing, MASCOT search program (http://www.matrixscience.com/) was used with significant threshold of 0.05 .

\section{DNA extraction, PCR amplification, and sequencing}

Total genomic DNA was extracted from the seedlings of Franklin, Yerong and all DH lines using Genomic DNA Extraction Kit (QIAGEN) following the manufacturer's instructions. For cloning and sequencing $M L O C \_12143.1$ and MLOC_65022.1 (encoding BATI-CMb and BATICMd) of Yerong and Franklin, two sets of primers (Additional file 1: Table S1) were designed according to the reference sequence from barley whole genome sequence [24]. The polymerase chain reaction (PCR) was conducted using LA Taq polymerase (TaKaRa), with annealing temperature of $62{ }^{\circ} \mathrm{C}$ and 32 cycles. After purification, the PCR products were transferred into the pGEM-T Easy Vector (Promega) following the kit's instruction. Then 20 positive clones of each gene were selected and sequenced.

For screening of gene specific markers, primers were designed by software Geneious 4.8 .3 according to the insertion and deletion (InDel) polymorphism between Yerong and Franklin (Additional file 1: Table S1). The PCR products were analyzed using $2.5 \%$ agarose gel electrophoresis.

\section{Results}

Phenotypic variation among the lines of Franklin/Yerong $\mathrm{DH}$ population

In 2009-2010 growing season, ACHD of Yerong was 20.33 EBC, being significantly lower than that of Franklin (25.67 EBC unit, $P<0.01$ ). As shown in Fig. 1, there was a large difference in ACHD among the lines of
Franklin/Yerong DH population. ACHD showed the normal distribution in the population in the two growing seasons. In 2009-2010 growing season, the mean ACHD of all examined DH lines was 18.25 EBC (Fig. 1). Transgression beyond the parental values could be observed. In 2010-2011 growing season, the mean ACHD of the examined lines was $16.73 \mathrm{EBC}$. The pairwise correlation

\section{$\mathrm{ACH} \mathrm{M}$ Control}

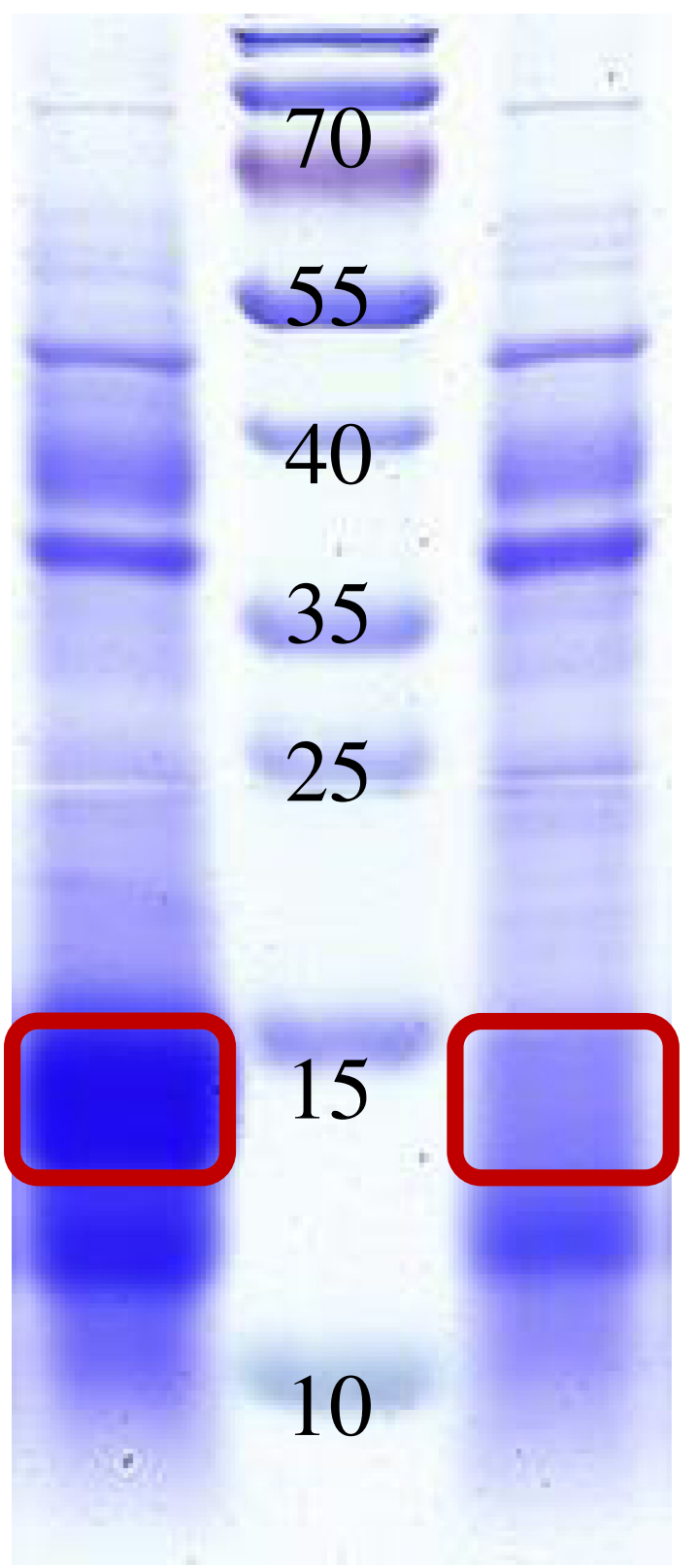

Fig. 3 SDS-PAGE analysis of turbid sediment (ACH) and clear supernatant (Control). The protein band in red frame was cut for LC-MS analysis, $M$ indicates protein ladder 
Table 2 LC-MS-identifiedproteins of MW $15 \mathrm{kDa}$ (as showed in red frame of Fig. 3) from ACH and Control

\begin{tabular}{|c|c|c|c|c|}
\hline Sample & Protein & $\mathrm{Gl}$ & $\mathrm{MW}(\mathrm{kDa})$ & Score \\
\hline \multirow[t]{4}{*}{$\mathrm{ACH}$} & Trypsin inhibitor CMe precursor & 1405736 & 16.34 & 99 \\
\hline & Glyceraldehyde-3-phosphate dehydrogenase & $34787348 / \underline{151943468}$ & 11.04 & $94 / \underline{218}$ \\
\hline & a-amylase/trypsin inhibitor CMb & 585290 & 17.20 & 86 \\
\hline & a-amylase/trypsin inhibitor CMd & 585291 & 19.14 & 68 \\
\hline \multirow[t]{4}{*}{ Control } & Glyceraldehyde-3-phosphate dehydrogenase & $34787348 / \underline{151943468}$ & 11.04 & $88 / \underline{236}$ \\
\hline & a-amylase/trypsin inhibitor CMb & 585290 & 17.20 & 81 \\
\hline & Pathogenesis-related protein 4 & 1808651 & 16.08 & 60 \\
\hline & a-amylase inhibitor BMAl-1 & 2506771 & 16.38 & 53 \\
\hline
\end{tabular}

Individual ions scores $>46$ indicate identity or extensive homology $(p<0.05), \mathrm{Gl}$ and score with underscore indicate the proteins were yeast original

coefficient of ACHD between the two years was significantly positive $(\mathrm{r}=0.62, P<0.01$, Additional file 2 : Figure S1).

\section{Identification of QTLs associated with alcohol chill haze in beer}

Only one QTL controlling ACHD was found on chromosome $4 \mathrm{H}$ in both growing seasons (Table 1, Fig. 2), with the nearest marker being bPb-8164. This QTL could explain around $20 \%$ of the phenotypic variation. The QTL was named as $q A C H$, a novel locus associated with beer haze stability.

The results of QTL analysis showed that the mean ACHD of Yerong' and Franklin' groups in the population was 14.31 and 18.73 EBC in 2009-2010 growing season, 14.87 and 20.94 EBC in 2010-2011 growing season, respectively (Table $1, P<0.01$ ). Obviously, ACHD of Yerong-derived genotypes is constantly lower than that of Franklin-derived genotypes.

\section{Identification of haze active proteins in beer}

The clear supernatant (Control) and haze sediment after alcohol chill test were analyzed by SDS-PAGE (Fig. 3). Many bands, ranging from $35 \mathrm{kDa}$ to $55 \mathrm{kDa}$ for both samples and from $10 \mathrm{kDa}$ to $15 \mathrm{kDa}$ for $\mathrm{ACH}$, were detected. These detected proteins could be derived from both brewing yeast and malt. In addition, there were a few of bands being larger than $55 \mathrm{kDa}$, indicating that during malting, mashing and brewing, some barley proteins of larger molecular weight are degraded to smaller proteins chemically and proteolytically. The bands ranging from 13 to $15 \mathrm{kDa}$ are particularly interesting, as a polymorphism was observed for the bands rich in $\mathrm{ACH}$, but relatively poor in Control. It may be suggested that the bands showing polymorphism might be the crucial haze active proteins influencing beer haze stability.

The special proteins ranging from $13 \mathrm{kDa}$ to $15 \mathrm{kDa}$ in both Control and $\mathrm{ACH}$ were excised and digested by trypsin for LC-MS/MS analysis. After LC-MS identification, corresponding peptide sequences were obtained. For data processing, MASCOT search program was performed at significant threshold of 0.05 , so as to provide the amino acid sequences, GI number and scores of the relevant proteins. The results showed that there were 4 kinds of proteins in each sample (Table 2). Trypsin inhibitor CMe precursor (BTI-CMe) and $\alpha$-amylase/ trypsin inhibitor CMd (BATI-CMd) were specifically detected in $\mathrm{ACH}$, indicating that they might be important alcohol chill haze active proteins. Glyceraldehyde-3phosphate dehydrogenase (GAPDH) and $\alpha$-amylase/ trypsin inhibitor $\mathrm{CMb}$ (BATI-CMb) were detected in both $\mathrm{ACH}$ and Control. As GAPDH was a constitutively expressed protein in barley and yeast, it should be a common protein in beer, not a haze active protein. In contrast, BATI-CMb was detected in $\mathrm{ACH}$ and it is quite similar to BATI-CMd, an identified haze active

Table 3 The chromosome location of the LC-MS identified proteins

\begin{tabular}{|c|c|c|c|c|}
\hline Proteins & $\mathrm{Gl}$ & Contig* & Chr. & $\mathrm{CM}^{*}$ \\
\hline Trypsin inhibitor CMe precursor & 1405736 & morex_contig_1571056 & $3 \mathrm{H}$ & 49.72 \\
\hline a-amylase/trypsin inhibitor CMb & 585290 & morex_contig_1562648 & $4 \mathrm{H}$ & 99.43 \\
\hline a-amylase/trypsin inhibitor CMd & 585291 & morex_contig_49644 & $4 \mathrm{H}$ & 99.43 \\
\hline Glyceraldehyde-3-phosphate dehydrogenase & 34787348 & morex_contig_1579793 & $7 \mathrm{H}$ & 70.54 \\
\hline Pathogenesis-related protein 4 & 1808651 & morex_contig_270946 & $3 \mathrm{H}$ & 148.65 \\
\hline a-amylase inhibitor BMAl-1 & 2506771 & morex_contig_113832 & $2 \mathrm{H}$ & 141.93 \\
\hline
\end{tabular}

* The information was from barley genome database (Mayer et al. 2012). Words in bold were the information about identified alcohol chill haze active proteins 


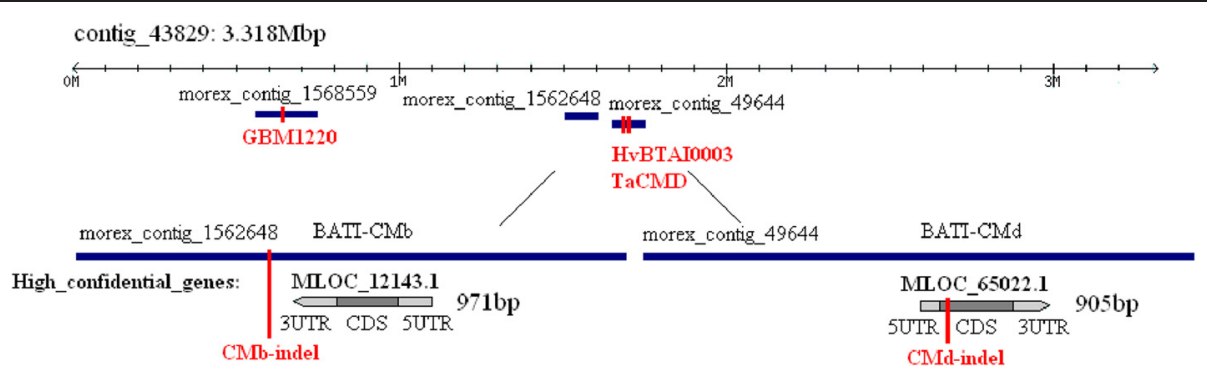

Fig. 4 Physical location of $q A C H$ associated markers, candidate genes (BATI-CMb, BATI-CMd), and corresponding gene specific markers (CMb-indel, CMd-indel). Words in red color indicatemarkers

protein. Hence it could be assumed that BATI-CMb is also an important alcohol chill haze active protein. The current results showed that BTI-CMe, BATI-CMb and BATI-CMd are the crucial haze active proteins in the 13-15 kDa bands.

\section{Genetic analysis of $q A C H$ and haze active proteins}

The LC-MS identified proteins were firstly searched in NCBI to obtain the corresponding nucleotide sequences, and then the nucleotide sequences were searched in barley genome database (Mayer et al. 2012) to obtain the corresponding gene locations (Table 3). The genetic locations of two haze active proteins, BATI-CMb and BATI-CMd, were at $99.43 \mathrm{cM}$ of chromosome $4 \mathrm{H}$, being similar with the genetic location of $q A C H$. Furthermore the two shotgun contigs (morex_contig_1562648, morex_contig_49644) where BATI-CMb and BATI-CMd exist were located at contig_43829 (Fig. 4).

Because there is no sequence data of DArT marker bpb-8164, three SSR markers closest to it were studied. From GrainGenes database (http://wheat.pw.usda.gov/ GG2/index.shtml), GBM1220, HvBTAI0003 and TaCMD were found to be $0 \mathrm{cM}$ distance from bpb-8164 in Barque 73/CPI 71284-48 population (Fig. 2). Moreover, it was found that the physical locations of the above three markers were at morex_contig_1568559, morex contig_49644 and morex_contig_49644, respectively. These shotgun contigs were all located at contig_43829 (Fig. 4). Therefore it may be concluded that bpb-8164 is located at contig_43829, or the site being very close to this contig.

From the fact that the physical locations of BATI-CMb and BATI-CMd are very close to the $q A C H$ associated marker (bpb-8164) (Fig. 4) and that BATI-CMb and BATI$C M d$ are alcohol haze active proteins (Fig. 3, Table 2), it may be deduced that BATI-CMb and BATI-CMd are candidate genes of $q A C H$, controlling haze stability of beer.

\section{Polymorphism of BATI-CMb and BATI-CMd}

The nucleotide and amino acid sequences of $B A T I-C M b$ and BATI-CMd in Yerong (low haze) and Franklin (high haze) were analyzed. According to the reference sequence from barley genome database, 2 sets of primers were designed to amplify $M L O C_{-} 12143.1$ and MLOC_65022.1 (encoding BATI-CMb and BATI$\mathrm{CMd})$. The gene structures were shown in Fig. 4. There was no intron in both genes. After amplification and sequencing, MLOC_12143.1 and MLOC_65022.1 of Franklin and Yerong were aligned by software Geneious 4.8.3. The results showed that there were 9 single nucleotide polymorphisms (SNPs) in the coding sequence (CDS) region of BATI-CMb between Yerong and Franklin (Additional file 3: Table S2). Seven SNPs were missense mutants among them, causing the changes of 5 amino acids. There were 6 bp deletions and 1 SNP in the CDS region of BATI-CMd between Yerong and Franklin (Additional file 4: Table S3). The 6 bp deletions caused loss of 2 amino acids for BATI-CMd in Franklin, indicating the change of amino acid may cause the difference in haze activity (Table 4). Moreover, there were several insertions, deletions and substitutions in the non-coding region of BATI-CMb and BATI-CMd (Additional file 3: Table S2 and Additional file 4: Table S3), which might result in the difference of expression level.

Table 4 The difference in amino acid composition of BATI-CMb and BATI-CMd in Franklin and Yerong

\begin{tabular}{llll}
\hline & Sequence NO. & Franklin & Yerong \\
\hline BATI-CMb & 18 & isoleucine $^{2}$ & threonine $^{1}$ \\
& 28 & glutamic acid $^{1}$ & lysine $^{1}$ \\
& 57 & methionine $^{2}$ & threonine $^{1}$ \\
& 119 & alanine $^{2}$ & threonine $^{1}$ \\
& 122 & phenylalanine $^{2}$ & tyrosine $^{1}$ \\
& 133 & phenylalanine $^{2}$ & tyrosine $^{1}$ \\
BATI-CMd & 140 & serine & tryptophan $^{2}$ \\
& 21 & - & alanine $^{2}$ \\
& 22 & - & alanine $^{2}$ \\
\hline
\end{tabular}

1: hydrophilic amino acid, 2: hydrophobic amino acid,-: deletion 


\section{Development of molecular markers}

Based on the sequence data (Additional file 5), gene specific markers were developed for $B A T I-C M b$ and $B A T I-C M d$. The locations of two markers (CMb-indel and CMd-indel) are shown in Fig. 4. The two markers can clearly distinguish Yerong, Franklin and DH lines (Fig. 5). The PCR products of Yerong and Franklin were $148 \mathrm{bp}$ and $120 \mathrm{bp}$ in the CMb-indel marker, $114 \mathrm{bp}$ and $108 \mathrm{bp}$ in the CMd-indel marker, respectively. After screening the DH population, it was found that the two markers were closely linked. There was no recombinant line in Franklin/Yerong population. So it is hard to determine which haze active protein is more important for haze formation in beer. Combined with initial markers found in Franklin/Yerong DH population, a new genetic map was constructed, and then QTL for alcohol chill haze was analyzed again. As a result, $q A C H$ was located at the same position, thus confirming that BATI-CMb and BATI-CMd are indeed the genes controlling beer chill haze.

\section{Discussion}

Evaluation of the difference among malt barley cultivars (genotypes) in beer haze formation and identification of the major factors controlling haze formation are dependent on availability of mini-scale beer preparation in laboratory and the haze-reflecting indicators. In this study, a small barley sample (200 g) of Franklin/Yerong $\mathrm{DH}$ population was used to produce beer using micromalting and micro-brewing according to Cai et al. [16] and Stewart et al. [17] with some modification. In addition, we used ACHD value to indicate the extent of haze formation in beer, since it could predict the colloidal stability and shelf life of beer [18].

A normal distribution of ACHD value among all lines of the $\mathrm{DH}$ population indicates that $\mathrm{ACH}$ may be controlled by multiple genes. Only one QTL was identified for ACHD, and it can explain about $20 \%$ of the phenotypic variation and has been located on chromosome $4 \mathrm{H}$. In our knowledge, it is the first QTL reported so far to be associated with beer haze stability, and is named as $q A C H$. By analysis of proteomics and bioinformatics, a protein, BATI-CMd was detected in $\mathrm{ACH}$. This protein is very similar to an identified haze active protein BATI$\mathrm{CMb}$ [7]. Accordingly, we assumed that BATI-CMd might also be an important alcohol chill haze active protein. Genetic analysis of $q A C H$ and the potential haze active proteins showed that the physical locations of both $B A T I-C M b$ and $B A T I-C M d$ were very close to the $q A C H$ associated marker (bpb-8164) (Fig. 4), suggesting that both $B A T I-C M b$ and BATI-CMd are critical alcohol haze active proteins controlling haze stability in beer.

Similar to the previously reported haze active protein BATI-CMe [11, 25], BATI-CMb and BATI-CMd belong to chloroform/methanol soluble $(\mathrm{CM})$ proteins. The mechanism for haze formation of BATI-CMb and BATICMd could be similar to that of BTI-CMe. The CM proteins belong to the trypsin/ $\alpha$-amylase inhibitor family and make the function in the defense of plants against their bio-aggressors [26, 27]. They are highly expressed during the late stage of seed development and early stage of seed germination in endosperm [28], and are rich in cereal endosperm and heat-stable [29]. During malting and brewing from barley grains, most present heatstable proteins are disulfide-rich proteins, including trypsin/ $\alpha$-amylase inhibitors [29]. Hence, after malting and brewing, the CM proteins are still abundant and stable in beer. In addition, the CM proteins are rich in cysteine, which is easy to form disulfide bonds and hydrophobic groups. Therefore, the mechanism of haze formation for BATI-CMb and BATI-CMd might be their abundance in beer and easy to form hydrophobic groups. For further investigation, extraction or recombination of these haze active proteins should be highly addressed.

The amino acid sequences differed between the two genotypes (Table 4). In particular for BATI-CMb, there were 5 hydrophobic amino acids in Franklin, whereas there was only a hydrophilic amino acid in Yerong. The difference could be considered as a major cause of the different haze formation in the two genotypes and also suggests the possibility of reducing haze formation in beer through genetic improvement of malt barley cultivars.

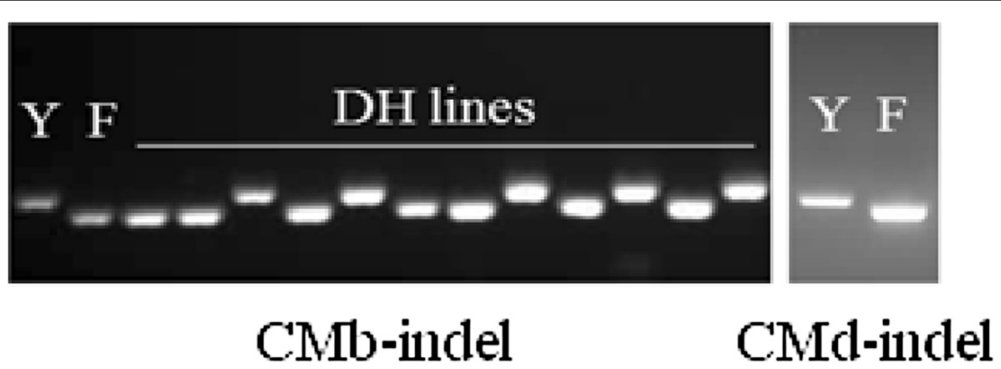

Fig. 5 The PCR results of InDel markers screening Franklin, Yerong and their DH lines. Y, Yerong; F, Franklin 


\section{Conclusion}

In conclusion, we identified a novel QTL, $q A C H$ controlling chill haze of beer and two key haze active proteins, BATI$\mathrm{CMb}$ and BATI-CMd. Bioinformatics analysis further suggests that BATI-CMb and BATI-CMd are the candidate genes associated with beer chill haze. The genotypic difference in haze formation could be attributed to different nucleotide sequence of BATI-CMb and BATI-CMd.

\section{Availability of supporting data}

The data sets supporting the results of this article are included within the article and its additional files.

\section{Additional files}

Additional file 1: Table S1. The primers involved in cloning and developing molecular makers about BATI-CMb and BATI-CMd.

Additional file 2: Figure S1. The correlation of ACHD between the two growing years.

Additional file 3: Table S2. The SNPS and InDels of BATI-CMb

(MLOC_12143.1) between Franklin and Yerong.

Additional file 4: Table S3. The SNPs and InDels of BATI-CMd

(MLOC_65022.1) between Franklin and Yerong.

Additional file 5: Sequence information of $M L O C \_12143.1$ and MLOC_65022.1 in Yerong and Franklin.

\section{Abbreviations}

ACH: Alcohol chill haze; ACHD: Alcohol-chill haze degree; BATI-CMb: CMb component of barley tetrameric a-amylase inhibitor; BATI-CMd: CMd component of barley tetrameric a-amylase inhibitor; BDAl-1: Barley dimeric a-amylase inhibitor; BTI-CMe: Barley trypsin inhibitor CMe precursor; CDS: Coding sequence; CM protein: Chloroform/methanol soluble proteins: $\mathrm{DH}$ : Double haploid; EBC: European brewery convention; InDel: Insertion and deletion; LC-MS: High performance liquid chromatography-tandem mass spectrometry; QTL: Quantitative trait loci; SNP: Single nucleotide polymorphism.

\section{Competing interests}

The authors declare that they have no competing interests.

\section{Authors' contributions}

$L Y, C L$ and $G Z$ designed research. $L Y, Y H$ and $H N$ performed research. $L Y, F D$, $C L$ and $G Z$ analyzed data. $L Y, M Z$ and $G Z$ wrote the paper. All authors have read, edited and approved the current version of the manuscript.

\section{Acknowledgements}

We are grateful to financial support by Natural Science Foundation of China (31171544, 31330055 and 31201166), 948 Project, Ministry of Agriculture, China (2012-Z25) and China Agriculture Research System (CARS-05). We also thank professors R. G. Xu of Yangzhou University, and J Lu of Jiangnan University, China for their kind help in micro-malting and brewing, respectively

\section{Author details}

${ }^{1}$ Agronomy Department, Zhejiang University, Hangzhou 310058, People's Republic of China. 'Department of Agriculture and Food, Western Australia, 3 Baron-Hay Court, South, Perth, Australia. ${ }^{3}$ Tasmanian Institute of Agriculture, University of Tasmania, P.O.Box 46, Kings Meadows, TAS 7249 Hobart, Australia.

Received: 10 February 2015 Accepted: 1 June 2015

Published online: 11 June 2015

\section{References}

1. Asano K, Shinagawa K, Hashimoto N. Characterization of haze-forming proteins of beer and their roles in chill haze formation. J Am Soc Brew Chem. 1982;40(4):147-54.

2. Siebert KJ, Troukhanova NV, Lynn PY. Nature of polyphenol-protein interactions. J Agric Food Chem. 1996;44(1):80-5.

3. Siebert KJ. Effects of protein-polyphenol interactions on beverage haze, stabilization, and analysis. J Agric Food Chem. 1999:47(2):353-62.

4. Leiper KA, Stewart GG, McKeown IP. Beer polypeptides and silica gel - part I Polypeptides involved in haze formation. J I Brewing. 2003;109(1):57-72.

5. Siebert KJ, Lynn PY. Mechanisms of adsorbent action in beverage stabilization. J Agric Food Chem. 1997;45(11):4275-80.

6. McMurrough I, Madigan D, Kelly R. Evaluation of rapid colloidal stabilization with polyvinylpolypyrrolidone (PVPP). J Am Soc Brew Chem. 1997:55(2):38-43.

7. limure T, Nankaku N, Watanabe-Sugimoto M, Hirota N, Zhou TS, Kihara M, et al. Identification of novel haze-active beer proteins by proteome analysis. J Cereal Sci. 2009:49(1):141-7.

8. Jin B, Li L, Li B, Liu BG, Liu GQ, Zhu YK. Proteomics study of silica eluent proteins in beer. J Am Soc Brew Chem. 2009;67(4):183-8.

9. Robinson LH, Juttner J, Milligan A, Lahnstein J, Eglinton JK, Evans DE. The identification of a barley haze active protein that influences beer haze stability: cloning and characterisation of the barley SE protein as a barley trypsin inhibitor of the chloroform/methanol type. J Cereal Sci. 2007;45(3):343-52.

10. Ye L, Dai F, Qiu L, Sun D, Zhang G. Allelic diversity of a beer haze active protein gene in cultivated and Tibetan wild barley and development of allelic specific markers. J Agric Food Chem. 2011;59(13):7218-23.

11. Ye L, Huang L, Huang Y, Wu D, Hu H, Li C, et al. Haze activity of different barley trypsin inhibitors of the chloroform/methanol type (BTI-CMe). Food Chem. 2014;165:175-80.

12. Marquez-Cedillo LA, Hayes PM, Jones BL, Kleinhofs A, Legge WG, Rossnagel BG, et al. QTL analysis of malting quality in barley based on the doubled-haploid progeny of two elite North American varieties representing different germplasm groups. TheorApplGenet. 2000;101(1-2):173-84.

13. Mather D, Tinker N, LaBerge D, Edney M, Jones B, Rossnagel B, et al. Regions of the genome that affect grain and malt quality in a North American two-row barley cross. Crop Sci. 1997;37(2):544-54.

14. Li CD, Tarr A, Lance RCM, Harasymow S, Uhlmann J, Westcot S, et al. A major QTL controlling seed dormancy and pre-harvest sprouting/grain alpha-amylase in two-rowed barley (Hordeum vulgare L.). Aust J Agric Res. 2003;54(11-12):1303-13.

15. Dai F, Qiu L, Ye LZ, Wu DZ, Zhou MX, Zhang GP. Identification of a Phytase Gene in Barley (Hordeum vulgare L.). PLoS One. 2011;6(4):e18829.

16. Cai SG, Yu G, Chen XH, Huang YC, Jiang XG, Zhang GP, et al. Grain protein content variation and its association analysis in barley. BMC Plant Biol. 2013;13:35.

17. Stkwart DC, Hawthorne D, Evans DE. Cold sterile filtration: a small scale filtration test and investigation of membrane plugging. J I Brewing. 1998;104(6):321-6.

18. Chapon L. Nephelometry as a method for studying the relations between polyphenols and proteins. J I Brewing. 1993;99(1):49-56.

19. Lopez M, Edens L. Effective prevention of chill-haze in beer using an acid proline-specific endoprotease from Aspergillus niger. J Agric Food Chem. 2005;53(20):7944-9.

20. McCarthySL MGD, Pringle AT. Comparison of rapid physical stability tests. J Am Soc Brew Chem. 2005;63:69-72.

21. Li H, Vaillancourt R, Mendham N, Zhou M. Comparative mapping of quantitative trait loci associated with waterlogging tolerance in barley (Hordeum vulgare L.). BMC Genomics. 2008;9(1):401.

22. Van Ooijen J. MapQTL ${ }^{\oplus}$ 5, Software for the mapping of quantitative trait loci in experimental populations. Wageningen: Kyazma BV; 2004

23. Schagger $H$. Tricine-SDS-PAGE. Nat Protoc. 2006;1(1):16-22.

24. Mayer KFX, Waugh R, Langridge P, Close TJ, Wise RP, Graner A, et al. A physical, genetic and functional sequence assembly of the barley genome. Nature. 2012;491(7426):711-6

25. Ye LZ, Dai F, Qiu L, Sun DF, Zhang GP. Allelic diversity of a beer haze active protein gene in cultivated and Tibetan wild barley and development of allelic specific markers. J Agric Food Chem. 2011;59(13):7218-23. 
26. Franco OL, Rigden DJ, Melo FR. Grossi-de-Sá MF: plant a-amylase inhibitors and their interaction with insect a-amylases. European J Biochem. 2002;269(2):397-412.

27. Jones BL, Fontanini D. Trypsin/a-amylase inhibitors inactivate the endogenous barley/malt serine endoproteinase SEP-1. J Agric Food Chem. 2003;51(19):5803-14.

28. Potokina E, Sreenivasulu N, Altschmied L, Michalek W, Graner A. Differential gene expression during seed germination in barley (Hordeum vulgare L.). Funct Integr Genomics. 2002;2(1-2):28-39.

29. Perrocheau L, Rogniaux H, Boivin P, Marion D. Probing heat-stable water-soluble proteins from barley to malt and beer. Proteomics. 2005;5(11):2849-58.

\section{Submit your next manuscript to BioMed Central} and take full advantage of:

- Convenient online submission

- Thorough peer review

- No space constraints or color figure charges

- Immediate publication on acceptance

- Inclusion in PubMed, CAS, Scopus and Google Scholar

- Research which is freely available for redistribution 